\title{
Feeding the future: developing the skills landscape in the agri-food sector
}

\author{
Cassie Sims, ${ }^{a^{*}} \odot$ Joseph Oddy, ${ }^{b}$ Lauren E Hibbert, ${ }^{c, d}$ Amy S Newell, \\ Luca Ruth Steel, ${ }^{\mathrm{f}, \mathrm{g}}$ Alastair T Gibbons, ${ }^{\text {h }}$ Nicola Caporaso, ${ }^{\mathrm{i}, \mathrm{j}, \mathrm{k}}$ Claire Duménil, \\ Sophie Read ${ }^{\mathrm{m}, \mathrm{n}}$ and Reuben CP Margerison ${ }^{\circ}$
}

\begin{abstract}
The agri-food sector and supply chain is a foundational component of society and is required for healthy populations across the globe. Feeding the world, not only with enough calories, but with nutritious food that has been sustainably sourced and processed, is a continuous and developing challenge. Despite this, careers in research and development opportunities in the agri-food sector have less visibility in comparison to other sectors, and we argue that agri-food remains under-represented in education and training, from school through to higher education. In this perspective, we explore how diversity in people, skills and education contributes to the agri-food sector, and how fostering this diversity could help to solve some of the big challenges faced in 2021 and beyond. Specific focus is given to education and training schemes, and the lack of agri-food topics in relevant science degrees.

(c) 2021 Society of Chemical Industry (SCI).
\end{abstract}

Supporting information may be found in the online version of this article.

Keywords: biotechnology; molecular biology; biochemistry; ecology; environmental chemistry; environmental biotechnology

\section{CHALLENGES IN AGRI-FOOD: GLOBAL CHANGE AND SKILLS GAPS}

The agri-food sector incorporates all areas of food production, from field to fork. It generates a large proportion of global greenhouse gas emissions, but also is uniquely placed to deal with many of the global challenges humanity currently faces. ${ }^{1}$ There are few sectors which have the potential to play a major role in achieving more than one of the United Nations Sustainable Development Goals (UN SDGs). ${ }^{2}$ Agri-food will be critical to achieving at least four of the UN SDGs: the achievement of no poverty (Goal 1), zero hunger (Goal 2), good health and wellbeing (Goal 3), and responsible consumption and production (Goal 12), whilst also being peripheral to many other SDGs. Although the agri-food sector can contribute to solutions in numerous ways, it faces many challenges that will impede progress towards achieving these goals. First, climate change causes significant problems for the agri-food sector, principally because increased global temperatures and extreme weather events negatively impact crop production. ${ }^{3}$ Secondly, agri-food also is affected by the downstream effects of carbon emissions, such as increased number of pests and diseases as well as resource supply problems which affect how food is produced, supplied and consumed. ${ }^{4,5}$ Thirdly, there is a need to provide nutritious food which must be balanced against conservation efforts and biodiversity preservation, with innovative solutions that require less inputs as well as land. ${ }^{6}$

Beyond the cultivation of crops, the quality, safety and efficiency of food production is another major concern for the agrifood sector. Food waste during processing, packaging and
* Correspondence to: C Sims, Department of Biology, Lund University, Ekologihuset, Sölvegatan 37, 22362 Lund. E-mail: cassie.sims@biol.lu.se

a Department of Biology, Lund University, Lund, Sweden

b Department of Plant Sciences, Rothamsted Research, Harpenden, UK

c School of Biological Sciences, University of Southampton, Southampton, UK

d Department of Plant Sciences, UC Davis, Davis, CA, USA

e Natural Sciences, Lancaster University, Lancaster, UK

f Department of Biointeractions and Crop Protection, Rothamsted Research, Harpenden, UK

g School of Life Sciences, University of Nottingham, Nottingham, UK

h UKRI-BBSRC, Swindon, UK

i QualySense AG, Glattbrugg, Switzerland

j Department of Food Science, School of Biosciences, University of Nottingham, Nottingham, UK

k Department of Agriculture, University of Naples Federico II, Napoli, Italy

I Independent Scholar, Trentino, Italy

m School of Agriculture, Policy and Development, University of Reading, Reading, UK

n Collaborative Training Partnership for Fruit Crop Research, NIAB EMR, East Malling, UK

- Department of Earth and Environmental Sciences, University of Manchester, Manchester, UK 
consumption further reduces the impact of already limited yields. In Europe, approximately $20 \%$ of total food produced is wasted or spoiled, and in the UK alone, it is estimated that 13.1 million tonnes of food is wasted per annum. ${ }^{7,8}$ Populations across the globe also face a number of health issues caused by poor and unbalanced nutrition such as type II diabetes, cardiovascular disease and obesity. ${ }^{3}$ Minimizing food losses through optimization of the supply chain, whilst ensuring a safe and healthy final product, will require many changes to all parts of the food system - a significant scientific and logistical challenge.

Innovative solutions are required, as environmental protection and sustainability must be combined with practicality. Attempts to improve sustainability through schemes such as organic farming may result in lower production yields and increased labour costs. ${ }^{9}$ Going forward, we must ensure that innovation in agronomy, food processing equipment and food packaging minimize the footprint of the sector on the planet without decreasing output, especially as populations are growing and there is continuing need for increased food production worldwide.

Coordination at a global level helps to set the direction for solutions to overcome such challenges, but much of the change will need to be implemented at the national level. In the UK, the agri-food sector contributed $£ 120.2$ billion to national gross value added in 2018, forming a large proportion (9.4\%) of the UK's economy. ${ }^{10}$ The sector also contributes a similar proportion (10\%) to the UK's greenhouse gas emissions, and in 2019, the UK became the first major economy in the world to pass laws committing to end its contribution to global warming by $2050 .^{11}$ In order for the agri-food sector to achieve net-zero, three broad areas have been identified: (i) improving farming's productive efficiency; (ii) improving land management and changing land use to capture more carbon; and (iii) boosting renewable energy and the wider bioeconomy. ${ }^{12}$ Additionally, the UK's departure from the European Union (EU) may significantly impact on both the operation and regulation of the agri-food sector, as well as education and training within science. ${ }^{13,14}$ In order to address these current and future issues, we must ensure that the workforce is equipped with the necessary skills through appropriate education and training in the agri-food sector.

Here we define agri-food education as the total sum of the training and education that occurs throughout the sectors involved with the different stages of food production, from the cultivation of crops in the field to the consumption of the final food product. It is therefore important not only to have adequately trained technical workers (e.g. agronomists, plant pathologists, food technologists, food engineers), but also to provide training to the farmers and operators of all stages of the food chain, because efficient primary production and processing rely on their work. Education and training in this sector includes a range of traditional and nontraditional pathways, such as dedicated higher education courses, apprenticeships and employment in agricultural and food businesses. Crafting a diverse workforce with the tools to tackle the climate, waste and health issues associated with the food production system, appropriate training and education in the agri-food sector is vital.

The challenges involved in the agri-food section span multiple disciplines, and therefore the entire agri-food chain requires innovative solutions from teams with diverse skill sets. ${ }^{15}$ Education in relevant traditional STEM (Science, Technology, Engineering and Mathematics) subjects, including Biology, Biochemistry and Chemistry, will provide skills that are extremely valuable in tackling agri-food's challenges, but students must be exposed to relevant topics through their curricula, additional training or opportunities in order to develop careers in agri-food. Furthermore, it is crucial that a career in agri-food is accessible to people from all backgrounds and educational disciplines as the sector is not exempt from systemic problems related to impaired accessibility, gate-keeping and limited diversity.

\section{THE STATE OF AGRI-FOOD EDUCATION AND TRAINING IN THE UK}

The agri-food sector, from education to further careers, must ensure a diverse workforce with equal access to careers for everyone. In 2021, people from diverse backgrounds, including the LGBTQIA+ community, women and individuals identifying as nonbinary, and/or those belonging to Black, Asian and minority ethnic backgrounds still remain disproportionately represented and face systemic inequalities, biases and obstacles to a career in STEM. The agri-food sector is no exception to this. A diverse community of people is needed in agri-food, not only for representation, but also to provide different perspectives to address the major challenges in the sector. Diversity in research and innovation teams is invaluable for the success and progress of the next generation of scientists. ${ }^{15}$

In the 2019/20 academic year, there were 16725 higher education students in 'Agriculture, food and related studies' according to the Higher Education Statistics Agency (HESA). ${ }^{16}$ Of these, $35.8 \%$ (5995 individuals) were 'male' and 64.1\% (10 730 individuals) were 'female' and $<0.1 \%$ (15 individuals) 'other'. This bias is unique within scientific disciplines, with other subjects tending to have an even male: female gender split or male bias. ${ }^{16}$ Despite a female bias in higher education, the agri-food industry is traditionally male-dominated; for example, a 2016 survey by DEFRA revealed that $84 \%$ of farm holders and $83 \%$ of farm managers in England were male. ${ }^{17}$ Charters such as the Athena SWAN gender equality scheme, commissioned by the Equality Challenge Unit, exist for higher education institutions in the UK, although the importance of such schemes in university grant funding applications has been stepped down in recent years, leading to calls for their reformation. $^{18}$

Despite the female bias in agri-food degree disciplines, disproportionate representation of minority ethnicity backgrounds still exists. BAME (Black, Asian or Minority Ethnicity; this term is used to align with HESA terminology but is recognized by the authors as a nonoptimal term that does not reflect broader nuances that individuals from different backgrounds experience) students are disproportionately represented in Animal Science, Agricultural Sciences, Agriculture, Rural Estate Management, and Forestry and Arboriculture courses, compared with the general population (HESA) (Fig. 1). Similar disproportionate representation recently has been highlighted in geoscience courses. ${ }^{19}$ Advance Higher Education (Advance HE) does have a Race Equality Charter, similar to the Athena SWAN charter, to which universities can apply. However, HESA figures clearly show this is not enough to provide BAME students an accessible and visible route to many agri-food related courses.

Accessibility issues prevail beyond undergraduate higher education into postgraduate courses and eventually academic research positions. The proportion of studentships awarded by UKRI councils to candidates disclosing a disability increased by $4 \%$ over the last 6 years, but remains negligible compared with the proportion of awardees not disclosing a disability. ${ }^{20}$ Similar 


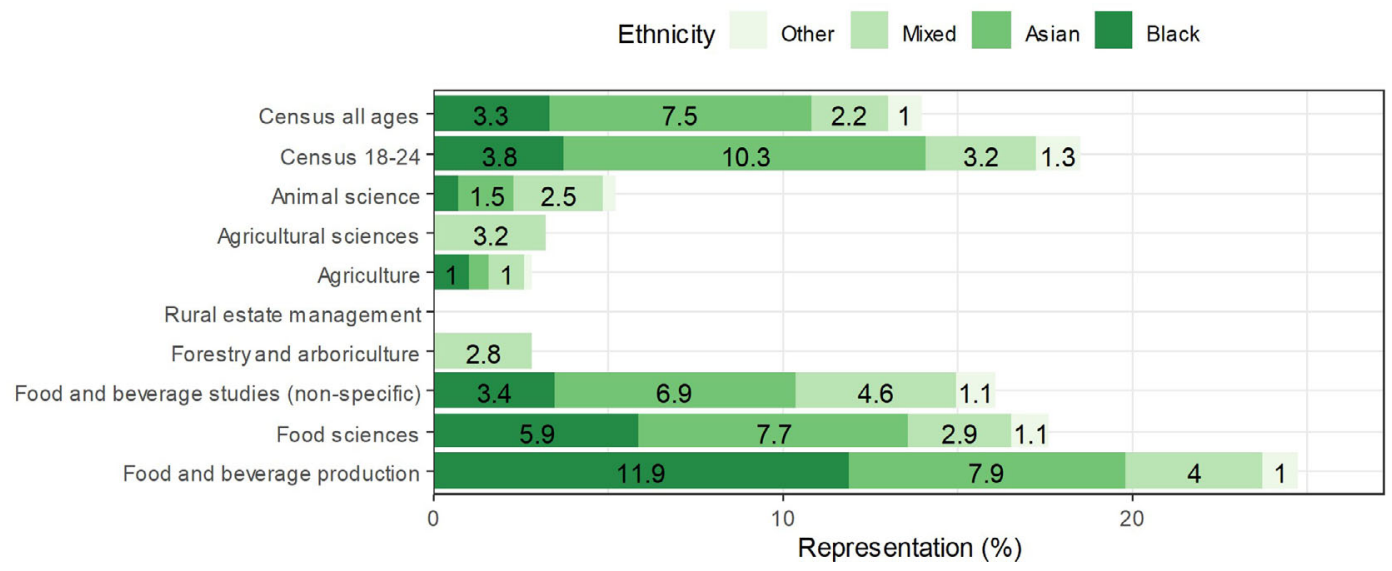

Figure 1. Proportion of students in a range of agri-food specific degrees that belong to a Black, Asian or Minority Ethnicity, compared with UK census data. Data from HESA, ${ }^{16}$ figure design inspired by Dowey et al. ${ }^{19}$ Percentage values $\geq 1 \%$ are shown.

statistics to HESA reports also are observed for fellowships and principal investigator awards for ethnicity. ${ }^{21}$

The increased awareness surrounding issues related to equality, equity and diversity in recent years has led to events that focus on encouraging and fostering diversity and being actively anti-racist in STEM and the academic community, including events such as \#ShutDownSTEM and \#BlackInSTEM weeks (summarized $\mathrm{in}^{22-24}$ ). Even though some events were of specific relevance to the agri-food community, such as \#BlackInBotany or \#BlackInEnvironWeek, there is still huge potential and a need for greater representation and encouragement of those from all backgrounds to a career in agri-food. Additionally, although some organizations exist to represent LGBTQIA+ people in STEM, including Pride in STEM and 500QueerScientists, there are limited organizations and campaigns dedicated to the representation of LGBTQIA+ people working in agri-food. Agrespect is a leading example of an organization dedicated to celebrating LGBTQIA+ people in rural, agricultural communities, and their pledge has been supported by a range of organizations from academia, industry and government. ${ }^{25}$ Organizations such as Agrespect have had great success so far, yet this only highlights the clear demand and need for additional organizations representing a broader range of identity and intersectionality.

Despite its significant value as an industry, topics related to agrifood remain under-represented in traditional science higher education. To investigate this, an initial search of the Universities and Colleges Admissions Service (UCAS) was conducted to determine the number of degree courses offered in agri-food related disciplines. A total of 274 courses in this field were found, with the highest proportion in the food science division compared to the smallest proportion in the plant division (Fig. 2). Many universities have separate departments for agri-food related disciplines such as Agriculture and Food Nutrition, but only two UK universities have separate Plant Science departments. ${ }^{26}$ Beyond specialist degree disciplines, such as Agricultural Sciences and Nutrition, agri-food related topics appear infrequently in degree curricula. Under the assumption that agri-food degree courses would contain agri-food related content, only degree courses related to broader life sciences and chemical sciences were surveyed in further detail.

In order to gain a comprehensive understanding of both where and how these topics are lacking, broader-disciplined science subject degrees based at UK institutions (Fig. 2; blue) were surveyed for agri-food topic content in offered modules. Agrifood content was noted if the available module description contained a reference to an agri-food related topic. These included mention of plant science, soil science, food and nutritional science, biosynthesis of plant-based natural products, biodiversity, plant biotechnology, livestock management, environmental chemistry and chemical ecology (full list in Additional Data S2).

In total, 9678 modules across 329 degree courses were surveyed, from UCAS and individual university website data. In general, physical sciences (Chemistry) had lower proportions of agri-food related modules than life sciences (Biology, Biochemistry, Biotechnology, Molecular Biology and Zoology), as expected (Fig. 3). Initial analysis focused on Chemistry and Chemical Science degree courses. A total of 2173 modules spanning 84 Chemistry courses were reviewed, with 110 modules (5.1\%) containing agri-food related topics. Additionally, for each course the proportion of modules containing agri-food was calculated (Fig. 3) and the average percentage of modules within a course containing agri-food calculated to be $5.7 \%$. A large proportion of degrees contained no modules mentioning agri-food related topics (39 courses, $46.4 \%$ ). Those modules which contained mention of agri-food topics were focused mainly on sustainability and green chemistry. Although sustainability is a topic of significance in agri-food, the application of chemistry and chemical sciences apply to approaches for a sustainable future is far more than the development of sustainable or green chemical processes. Chemistry can be used in the development of sustainable agricultural and food processes, effective crop management and understanding soil. Furthermore, skills gained in Chemistry degrees are transferable to other areas of research of the agri-food supply chain, from which the agri-food sector may benefit.

Notably, there were only two observable mentions of the term 'agrochemicals' in Chemistry degree course modules - in courses from The University of Manchester and University of Southampton. Despite downturns in the agrochemical industry resulting from low crop prices and regulation changes, threats of pesticide resistance and climate change persist; sustaining the need for innovative minds in the agrochemical industry is vital. ${ }^{27}$ This is particularly important in the development of novel active ingredients and application methods for agrochemicals. ${ }^{27}$ Chemistry education continues to focus on pharmaceuticals, and occasionally fine chemicals or formulation, as the focus of chemical production, despite agrochemicals and other speciality agri-food 


\section{Agriculture/Agricultural Sciences}

Agricultural Management

Animal Science

Botany/Plant Science

Food Science

Horticulture

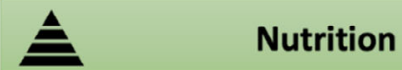

Veterinary Science

\section{4}

28

52

11

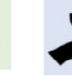

Biochemistry

59

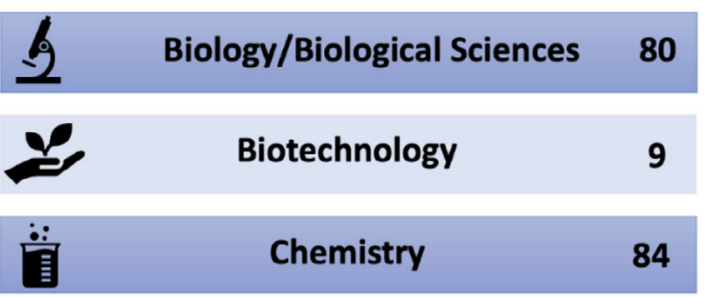

8

Molecular Biology/Microbiology 35

\section{0}
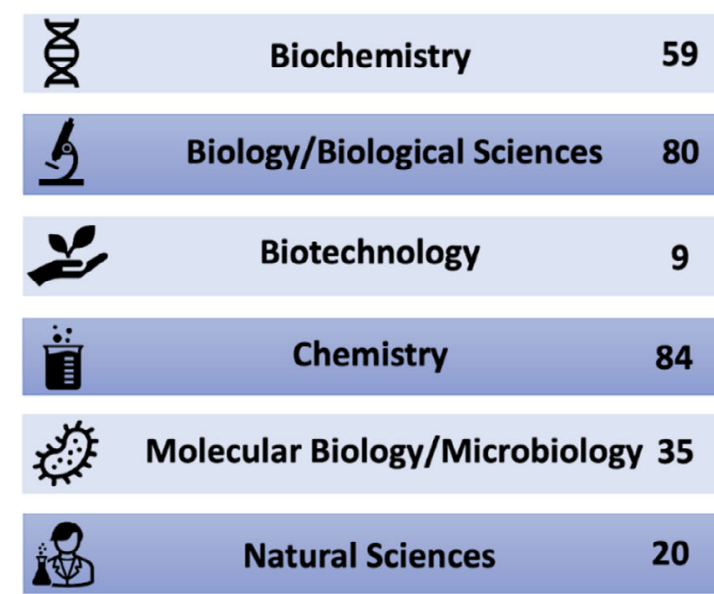

20

Figure 2. Number of degree courses found on UCAS in agri-food related disciplines (left, green), and broader life sciences and chemical sciences (right, blue).

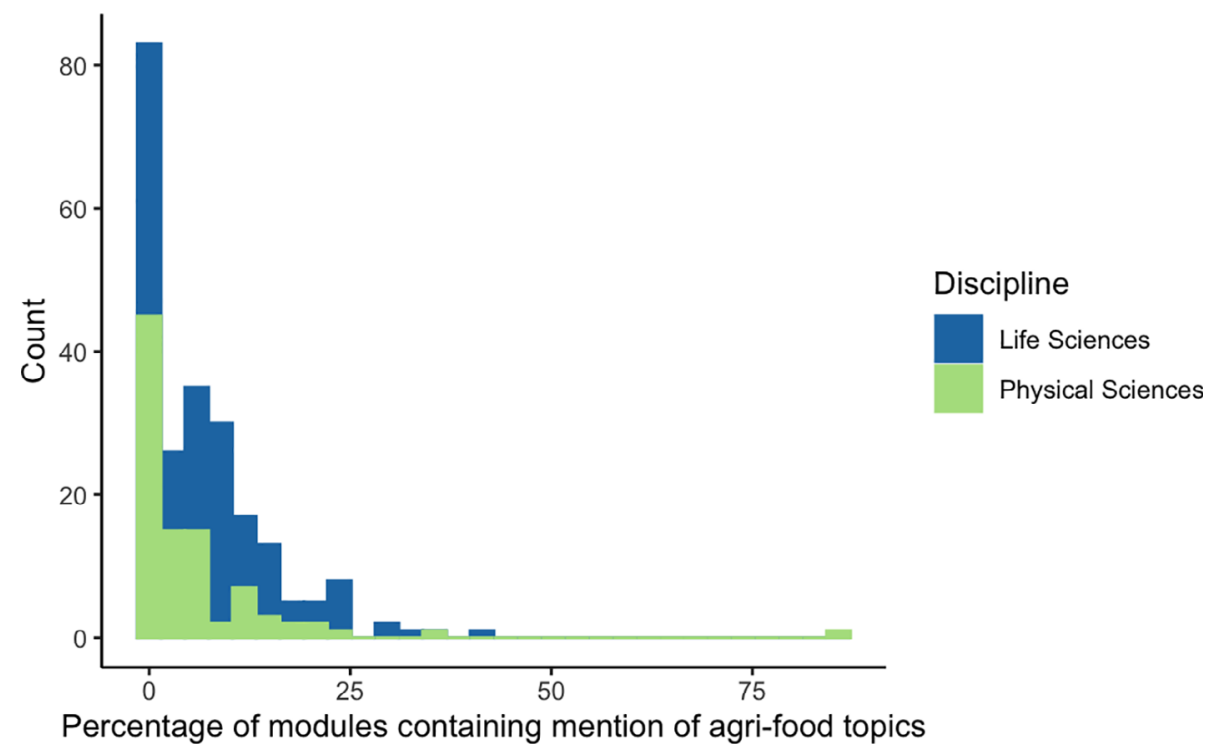

Figure 3. Histogram of the percentage of modules containing agri-food across 329 surveyed degree courses, split by physical ( 94 courses) and life sciences ( 235 courses). In both, a large number $(126,38.3 \%)$ of courses offer zero agri-food related modules. Datasets are overlapped.

related chemicals accounting for a portion of the chemical industry (Fig. 4).

In addition to Chemistry courses, other disciplines were evaluated including Biological Sciences, Biotechnology, Microbiology, Zoology and Natural Sciences (divided by Chemistry and Biology modules). A total of 7505 modules across 245 additional courses were discovered, with 529 modules (7.05\%) and 158 courses (64.5\%) containing agri-food representation. Although inclusion of life sciences resulted in higher figures, it still demonstrated a significant under-representation of agri-food related topics, with 126 courses not explicitly offering any modules relevant to agrifood. From life science subjects, more relevant agri-food topics
Production and Agricultural Biotechnology emerged, although this still represented a minority proportion of degree subjects (Fig. 5).

Natural Sciences degrees are designed to be interdisciplinary, and to cross conventional subject boundaries in order to enable research between the boundaries of various subjects. Therefore, it was not surprising that of the 18 Natural Sciences courses with accessible module data, 12 offered modules with an agri-food theme. Natural Sciences courses were analysed further only where the Natural Science degree course had bespoke modules not covered by other degree courses at the same institution, such as Biology and Chemistry. Of the eight degrees with majority bespoke modules, the University of Cambridge offered the most 


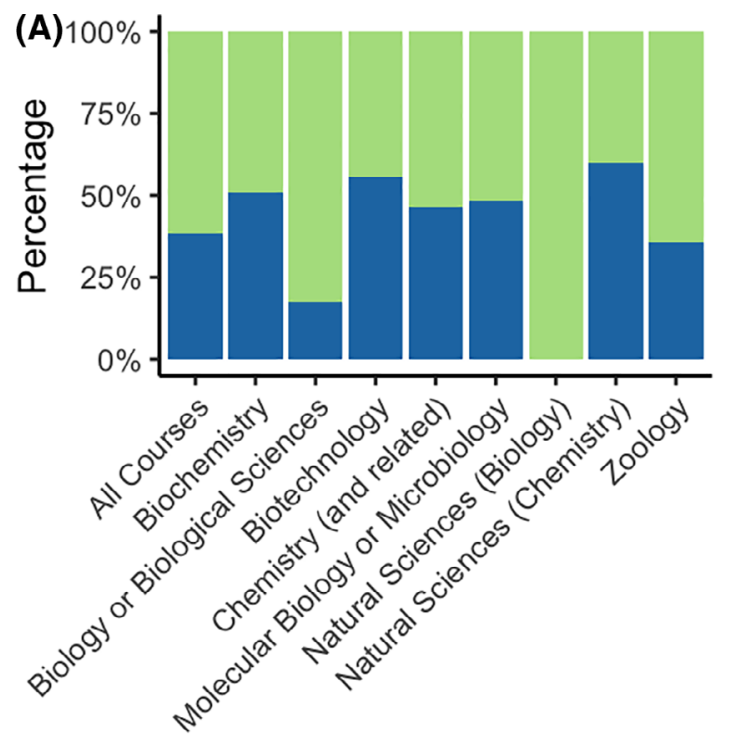

Course Title

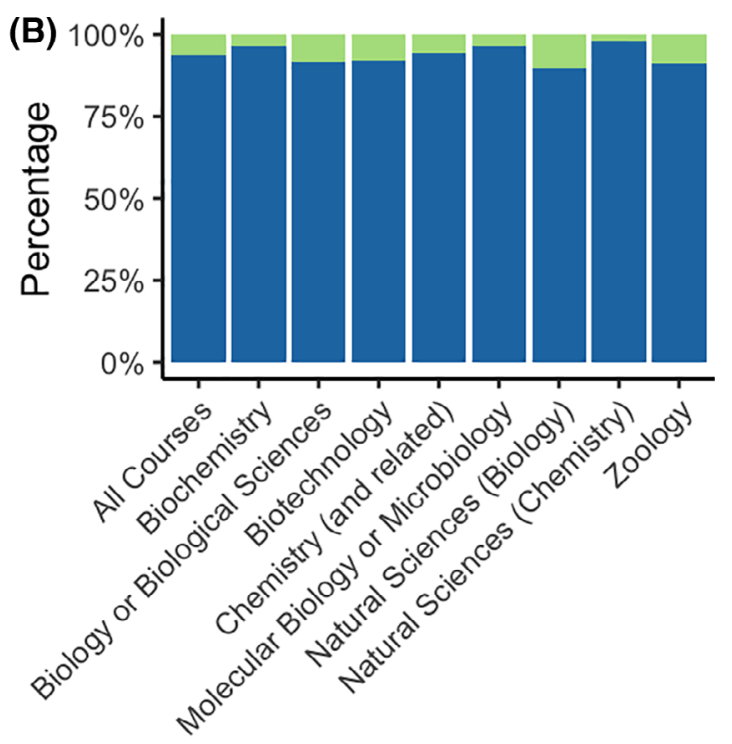

\section{Course Title}

Does not mention agri-food

Mentions agri-food

Figure 4. (A) Stacked bar chart displaying the proportion as a percentage of courses within a discipline that contain any mention of an agri-food related topic; (B) Total proportion of modules offered within a degree discipline that mentions agri-food.

modules (5 of 52 modules, $9.6 \%$ ) with an agricultural theme, followed by the University of Exeter (5 of 59 modules, $8.5 \%$ ).

In both physical and life sciences more general modules including Genetics or Microbiology may be relevant to agri-food in a broader sense, yet many of the examples and applications of these modules were quoted as medical, pharmaceutical or related to humans. Likewise, in Chemistry degrees, where topics around synthetic organic chemistry could be linked to insecticides, or inorganic chemistry to soils, limited examples were given to highlight the relevance and interesting topics of agri-food.

Unfortunately, lack of representation of agri-food related disciplines prevails beyond undergraduate degrees into postgraduate studies, particularly PhDs. The 'UK plant science research strategy: $a$ green roadmap for the next 10 years ${ }^{128}$ released by UK Research and Innovation (UKRI) in 2021, highlights the disparity between plant science and medical sciences; $427 \mathrm{PhD}$ studentships in plant science were funded over the last 5 years by BBSRC, and despite being a minority funder in the area, the Medical Research Council (MRC) funded around $2000 \mathrm{PhD}$ studentships in biomedical sciences in the same time period. The same report lays out clear recommendations for improving the diversity of both people and skills in plant science: provide initiatives and support for plant science-focused organizations, charities and learned societies, such as botanical gardens; raise the profile of plant science in the school curriculum and STEM subjects by working with societies across disciplines, such as the Royal Society of Chemistry and Institute of Physics; and increase the number of PhD studentships in the field and the funding and training opportunities of those interested. ${ }^{28}$

Due to the lack of agri-food topics in traditional educational routes, nontraditional forms of education and training should be promoted. A broad, systemic change in the curricula of UK higher education may be needed to improve grounding for careers in agri-food, but this is an immense challenge and will take time to achieve. Conversely, accessible smaller schemes, projects and events are required to expose people to agri-food careers. Even though a student may not get a direct introduction to agri-food related topics in their STEM degree, they may attend a summer school, research programme or industrial placement that exposes and highlights this fascinating and challenging sector. For example, the Gatsby Foundation's Plant Science Summer School provides the opportunity for undergraduate students to discover plant science through practical sessions and interactions with experts. A 5-year study showed that the Gatsby Summer School 'increased the pool of high-quality plant science related $\mathrm{PhD}$ applicants in the UK and has had a positive impact on students' career aspirations'. ${ }^{29}$

Major funding bodies in the UK also are attempting to address agri-food skills gaps; the Biotechnology and Biological Sciences Research Council's (BBSRC) Strategic Training Awards for Research Skills scheme previously funded a Crop Protection Summer School for UK undergraduates; crop protection is a significant, interdisciplinary field in agri-food. This was hosted by experts at Harper Adams University and ran for 3 years, targeting first and second year students with 'little or no agricultural content in their degrees' ${ }^{30}$ Additionally, influential multinational corporations within the agri-food sector are offering more opportunities for extracurricular engagement. For example, Bayer Crop Science has held the 'Youth Ag Summit' biennially since 2013, providing a 'unique opportunity to connect and empower the next generation of agricultural change-makers'. ${ }^{31}$ As a nontraditional education programme, the summit involves training, debate, workshops and talks from experts to equip young people with skills to tackle major agri-food challenges such as world hunger.

Beyond formal schemes related to the agri-food sector, more informal and situational factors can determine one's career, including mentors and advisors. Mentoring is a distinct, individual-based and deep engagement between either peers, groups or between two individuals in a hierarchical structure, 
such as a student and advisor. ${ }^{32}$ Mentoring can take many forms, but a good mentor aims to learn the personal strengths and weaknesses of a mentee and provides support for the mentee to achieve personal goals. ${ }^{33}$ Access to high-quality mentoring provides unique opportunities for agri-food students across all levels. ${ }^{34-36}$ Mentors who had traditional academic careers might not be able to provide practical advice on pursuing alternative career routes, therefore having a team of mentors with diverse backgrounds best showcases the range of possibilities to students. ${ }^{37}$ Transitioning from academia to industry, policy, or a nongovernmental organization (NGO) can be a steep learning curve, and engaging with industrial partners can lift persisting assumptions of science students about the skills and experiences needed for alternative career paths. ${ }^{38}$ High-quality mentoring and a sense of belonging also are key to encourage racial and ethnic diversity in STEM. ${ }^{39}$

The agri-food sector consists of many stakeholders and provides exciting opportunities for students who have valuable problemsolving skills but often, students are not exposed to the myriad of possibilities throughout their studies. Mentoring programmes provided by professional societies, such as the Society of Chemical Industry $(\mathrm{SCl})$, provide a platform to link people with different backgrounds and provide a basic framework for establishing and maintaining the mentoring relationship.

Skills development that extends beyond the traditional curriculum, and some that falls within, requires extensive funding and support to establish and maintain. The aforementioned schemes require significant funding to cover expenses, and often also consist of small grants which can allow students to start their own business ventures, develop further skills, or travel. Many universities now offer the opportunity for a professional placement of up to a year, allowing students to develop skills and experience in their chosen workplace. Although some agri-food institutes and companies advertise relevant positions, greater recruitment of these students to these agri-food placements would be beneficial. Likewise, short, funded research projects allow undergraduate students to experience life as a scientist within agri-food, develop research skills and report their own scientific discoveries. Several opportunities exist in agriculture and food-related research, such as the John Innes Centre's International Undergraduate Summer School, and the British Society for Plant Pathology's Undergraduate Vacation Bursary. ${ }^{40,41}$

In the UK, funding of postgraduate studies, particularly $\mathrm{PhD}$ programmes, is critical for the development of skilled researchers in these fields. A higher level of funding means more positions for students, and often produces both a higher quantity and quality of research outputs, as well as more opportunities to engage with high-risk high-reward projects. PhDs with increased funding also can lead to more opportunities for students to engage beyond the laboratory, run extensive field trials, visit field sites or work with industry partners. A significant portion of $\mathrm{PhDs}$ are funded by UKRl, including the funding of dynamic Doctoral Training Programmes (DTPs) and Collaborative Training Partnerships (CTPs), which often allow students to look beyond the narrow scope of their academic research. However, the council within UKRI dedicated to biosciences (BBSRC) traditionally funds only a limited number of PhDs in agri-food related topics, such as plant sciences, compared with the funding of other biological disciplines such as human health. ${ }^{28}$ In addition to there being a limited number of postgraduate places, many students in the UK have fewer opportunities to gain research experience as a Masters degree is a costly endeavour, and typically only lasts for 1 year. This is by contrast with European counterparts, who have the opportunity to study a longer degree in the specialism of their choice (usually 2 years), which are generally free or have inexpensive tuition fees - for comparison, a Master of Science (MSc) in Agricultural Sciences in the University of Helsinki, Finland has no tuition fees for EU students, lasts for 2 years and contains an extended research project. $^{42}$ A comparable UK-based degree, an Agricultural and Environmental Sciences MSc from Newcastle University, takes only 1 year, costs $£ 11400$ in fees for a home (UK National) student and has a shorter research project. ${ }^{43}$ Not only is a further degree with less incurred cost more attractive in general, it is inherently more accessible. Individuals must already have significant experience, such as aforementioned schemes and summer placements, a high standard of undergraduate degree and support or backing from other academics to access a Masters education. Reducing or abolishing tuition fees and providing the monetary support, education and placements that we discuss in this paper are critical for broadening equal opportunities and achieving equity in access to the field. Fairly distributed financial support is a significant way to level the playing field for all.

Beyond postgraduate education, students who choose an academic or more traditional research pathway are faced with a competitive funding market and often are competing with those who work across a broad range of scientific/academic disciplines. Those who choose to diversify their training, pursue entrepreneurial careers or move to industry are still faced with limited options, and it can be difficult to find funding to have mobility through career pathways.

Not only is the UK market for funding competitive, but since the UK's departure from the EU (Brexit), many UK students and researchers have lost significant access to funding schemes designed to expand their experiences and develop collaborations. For example, the UK is no longer part of the ERASMUS+ scheme, and its UK government replacement, the Turing Scheme, has been criticized beacuse, despite a greater focus on widening participation and inclusion of students from low-income backgrounds, it is yet to confirm benefits and funding that match those of ERASMUS.$+{ }^{44,45}$ In addition to limited access to EU-based opportunities for UK nationals, the UK can no longer expect an influx of talent from the EU, which will no doubt have consequential, detrimental effects on the diversity of talent in the UK agrifood sector in the future.

Overall, it is in the interest of professional societies, funding bodies, universities and agri-food companies to address the lack of agri-food education in the UK. It is therefore encouraging that extracurricular schemes exist and that evaluations show high retention of students within related disciplines. ${ }^{29}$ However, limited provision of agri-food modules in UK universities may mean that many students have a limited understanding or interest in relevant topics, so may be unlikely to apply for these schemes.

\section{MOVING FORWARD - CLOSING SKILLS GAPS AND OPENING OPPORTUNITIES}

It is clear that there are significant problems for the promotion and development of a workforce that includes diverse people and skills in agri-food. Despite the importance of this sector, it remains underrepresented in the curriculum, lacking in diversity, and underfunded for postgraduate studies. Traditional STEM degrees may offer the skills to tackle agri-food's grand challenges but graduates from these disciplines suffer from a lack of exposure to the topic. Although there are many invaluable schemes 


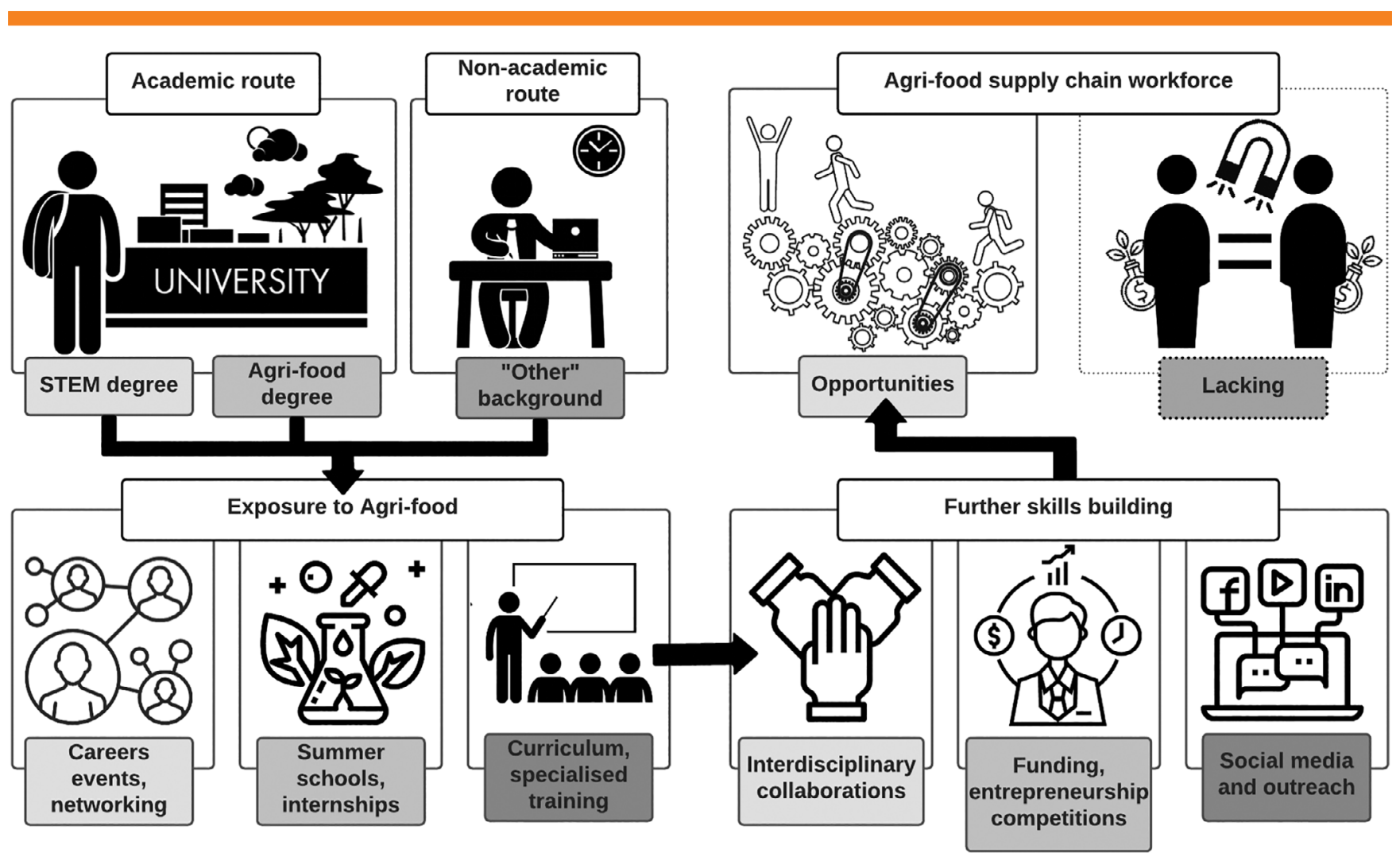

Figure 5. The challenges of accessing a career in research and development within the agri-food sector and opportunities for improvement.

which currently exist to increase exposure to agri-food and provide opportunities for students to experience the sector, there is still more that can be done (Fig. 5).

At the $\mathrm{SCl}$, our Agri-Food Careers committee is dedicated to careers in the agri-food sector and supply chain. We aim to improve the diversity of people and skills working in this sector, encourage cross-pollination and collaboration between different people in the industry, and showcase the excellent interdisciplinary work that is already underway in the field. Our efforts include organizing events through social media, such as our Twitter scientific photography competition, ${ }^{46}$ organizing webinars and other in-person events, creating articles and blogs. Our group ran its first peer mentoring scheme in 2021, where PhD and postdoctoral members from diverse backgrounds were matched with undergraduate and postgraduate students who were planning on applying for postgraduate research programmes abroad and in the UK. The mentors organized informal virtual meetings to share their experiences and offered to help with CVs and PhD applications. The mentees found this scheme helpful, especially during the COVID-19 pandemic, as some students had fewer or no previous informal opportunities to learn about postgraduate life.

Following our analysis of diversity, education and opportunities for those aiming to enter the agri-food sector, we offer the following recommendations to build opportunities, close skills gaps and continue developing careers in agri-food:

\section{Increasing diversity}

The agri-food sector must continue to strive to be an employment sector which is accessible for all. Efforts should be focused on diversity and equality in agri-food, as it is no exception to larger systemic problems. This can be achieved via myriad factors, and more in-depth studies must be conducted to focus on specific problem areas to identify valuable solutions.

\section{Enhancing agri-food representation in HE}

Traditional STEM subjects should be encouraged to include more agri-food related topics and examples in their curricula, and to make this information more visible to prospective students if they already do. In the traditional STEM subjects, it was clear that agrifood related topics appear infrequently, if at all. In particular there was an under-representation in Chemistry degrees; however, there were even some life sciences degrees without agri-food related modules.

\section{Promoting agri-food placements and industry exposure}

Universities and other education providers are encouraged to offer and sufficiently advertise placements and career opportunities in agri-food. This may form part of career education programmes, and should include diverse guest speakers or invited industrial companies.

\section{More industry-led recruitment}

Further to action by education institutes, individuals working in agri-food should be encouraged to work on recruitment and increasing awareness of their careers to those early in their career journeys. This should be supported by employers.

\section{Increasing funding for agri-food training}

Funding bodies, universities and industry must work together to increase the focus on agri-food related topics and develop proposals for agri-food specific funding programmes. There is a specific need to increase the number of opportunities for postgraduate studies or for training and skills development which 
go beyond traditional higher education. Development also should be considered at smaller scales, and societies such as $\mathrm{SCl}$ also can play a role in highlighting issues, and providing smallscale funding such as travel grants, entrepreneurship challenges and scholarships as a starting point.

The agri-food sector holds an important and unique position for global and national environmental and emission reduction efforts, the economy, and people's health and wellbeing. It is critical that this sector continues to recruit those with strong, interdisciplinary backgrounds who have had significant exposure to agri-food related topics. This can be achieved through education, training, mentoring, extra-curricular opportunities and funding, alongside systemic change and fostering of talent and diversity by organizations as a whole.

\section{ACKNOWLEDGEMENTS}

The authors would like to thank the Society of Chemical Industry for their ongoing support and funding of their committee activities. We would also like to thank Amma Simon and Hayley Moulding for their valuable comments and feedback on different aspects of the piece. We also would like to thank Juniper B. Kiss for their contributions to the manuscript and figure design.

JO is supported by a BBSRC Collaborative Training Partnership Studentship with partners University of Reading and Mondelez UK R\&D Ltd. LH is supported by a PhD studentship funded by Vitacress Salads Ltd. LS is supported by a BBSRC University of Nottingham-Rothamsted Research Doctoral Training Partnership (BB/M008770/1). RM was supported by a Biotechnology and Biological Sciences (BBSRC) Doctoral Training Partnership (reference 1792130).

\section{SUPPORTING INFORMATION}

Supporting information may be found in the online version of this article.

\section{REFERENCES}

1 Crippa M, Solazzo E, Guizzardi D, Monforti-Ferrario F, Tubiello FN and Leip A, Food systems are responsible for a third of global anthropogenic GHG emissions. Nat Food 2:198-209 (2021).

2 United Nations, Transforming Our World: The 2030 Agenda for Sustainable Development [Internet]. United Nations General Assembly (2015). Available: https://www.unfpa.org/resources/transformingour-world-2030-agenda-sustainable-development. [28 May 2021].

3 FAO, IFAD, UNICEF, WFP, WHO, The State of Food Security and Nutrition in the World 2020. Transforming Food Systems for Affordable Healthy. Rome (2020). Available: http://www.fao.org/3/ca9692en/online/ca9 692en.html. [28 May 2021].

4 Ziska LH, Bradley BA, Wallace RD, Bargeron $\mathrm{CT}$, LaForest $\mathrm{JH}$, Choudhury RA et al., Climate change, carbon dioxide, and pest biology, managing the future: coffee as a case study. Agronomy 8:1-21 (2018).

5 Agrimonti C, Lauro M and Visioli G, Smart agriculture for food quality: facing climate change in the 21 st century. Crit Rev Food Sci Nutr 61:971-981 (2021).

6 Macchi L, Decarre J, Goijman AP, Mastrangelo M, Blendinger PG, Gavier-Pizarro Gl et al., Trade-offs between biodiversity and agriculture are moving targets in dynamic landscapes. J Appl Ecol 57:20542063 (2020).

7 Stenmark Å, Jensen C, Quested T, Moates G, Buksti M, Cseh B et al., Estimates of European Food Waste Levels. Stockholm (2016). Available: https://www.eu-fusions.org/phocadownload/Publications/Estimate sofEuropeanfoodwastelevels.pdf. [28 May 2021].
8 Jeswani HK, Figueroa-Torres G and Azapagic A, The extent of food waste generation in the UK and its environmental impacts. Sustain Prod Consum 26:532-547 (2021).

9 Eyhorn F, Muller A, Reganold JP, Frison E, Herren HR, Luttikholt L et al., Sustainability in global agriculture driven by organic farming. Nat Sustain 2:253-255 (2019).

10 DEFRA, Food Statistics in Your Pocket: Food Chain (2020). Available: https://www.gov.uk/government/statistics/food-statistics-pocketbo ok/food-statistics-in-your-pocket-food-chain [24 May 2021].

11 The Carbon Trust, Sixth Carbon Budget (2020). Available: https://www. theccc.org.uk/wp-content/uploads/2020/12/The-Sixth-Carbon-Bud get-The-UKs-path-to-Net-Zero.pdf. [28 May 2021].

12 National Farmers Union, Acheiving Net Zero: Farming's 2040 Goal (2019). Available: https://www.nfuonline.com/nfu-online/business/ regulation/achieving-net-zero-farmings-2040-goal/. [28 May 2021].

13 Choi HS, Jansson T, Matthews A and Mittenzwei K, European agriculture after Brexit: does anyone benefit from the divorce? J Agric Econ 72:3-24 (2021).

14 Foster B, Brexit and scientific research ? Eur J English Stud 25:11-18 (2021).

15 Rizy C, Feil S, Sniderman B and Egan ME, Global Diversity and Inclusion: Fostering Innovation Through a Diverse Workforce [Internet] (2011). Available: https://images.forbes.com/forbesinsights/StudyPDFs/Inn ovation_Through_Diversity.pdf [28 May 2021].

16 Higher Education Statistics Agency. Personal Characteristics by Subject of Study [Internet]. Higher Education Statistics Agency (2019). Available: https://www.hesa.ac.uk/data-and-analysis/students/what -study/characteristics. [28 April 2021].

17 DEFRA. Agricultural Labour in England and the UK (2016). Available: https://assets.publishing.service.gov.uk/government/uploads/syste m/uploads/attachment_data/file/771494/FSS2013-labour-statsnoti ce-17jan19.pdf. [28 May 2021].

18 Equality and diversity efforts are not a 'burden.' Nature (2020). Available: https://doi.org/10.1038/d41586-020-03027-4

19 Dowey NJ, Barclay J, Fernando B, Giles S, Houghton J, Jackson CA-L et al., Tackling the geoscience racial diversity crisis in the Global North - a UK perspective. Nat Geosci 14:256-259 (2020).

20 UK Research and Innovation, Diversity results for UKRI funding data 2014-15 to 2019-20. 2020. Available: https://www.ukri.org/wpcontent/uploads/2021/03/UKRI-300321-DiversityResultsForUKRIFun dingData2014-20.pdf. [28 May 2021].

21 UK Research and Innovation, Detailed ethnicity analysis of funding applicants and awardees 2014-15 to 2018-19. 2019. Available: https://www.ukri.org/wp-content/uploads/2020/12/UKRI-15122020 -DetailedEthnicityAnalysisOfFundingApplicantsAndAwardees201415to2018-19.pdf. [28 May 2021].

22 Montgomery BL, Planting equity: using what we know to cultivate growth as a plant biology community. Plant Cell 32:3372-3375 (2020).

23 Subbaraman N, Thousands of scientists worldwide to go on strike for Black lives. Nature (2020). Available: https://www.nature.com/arti cles/d41586-020-01721-x.

24 Chen S, Researchers around the world prepare to \#ShutDownSTEM and "Strike For Black Lives". Science 80 (2020). Available: https:// www.sciencemag.org/news/2020/06/researchers-around-world-pre pare-shutdownstem-and-strike-black-lives. [28 May 2021].

25 Agrespect, Available: https://agrespect.com/ [22 April 2021].

26 Stagg P, Wahlberg M, Laczik A and Huddleston P, The uptake of plant sciences in the UK: a research project. Gatsby Charitabale Foundation/ Centre for Education and Industry, University of Warwick, Centre for Education and Industry, Warwick, United Kingdom (2009). Available: https://www.gatsby.org.uk/uploads/plant-science/reports/pdf/cei-up take-of-plant-science-in-uk-feb-09.pdf.

27 Phillips MWA, Agrochemical industry development, trends in R\&D and the impact of regulation. Pest Manag Sci 76:3348-3356 (2020).

28 Langdale J, UK Plant Science Research Strategy: A Green Roadmap for the Next Ten Years (2021). Available: https://www.ukri.org/news/tenyear-roadmap-to-guide-uk-plant-science/.

29 Levesley A, Jopson J and Knight C, The Gatsby plant science summer school: inspiring the next generation of plant science researchers. Plant Cell 24:1306-1315 (2012).

30 Leather S, CROPSS - inspiring biology students to consider careers in crop protection (2017). Available: www.harper-adams.ac.uk/blog/post/ 294/cropss-inspiring-biology-students-to-consider-careers-in-cropprotection [22 Apr 2021]. 
31 Bayer, Youth Ag Summit: Empowering the Next Generation. Available: www.cropscience.bayer.com/who-we-are/events/youth-ag-summit [22 Apr 2021].

32 Montgomery BL, Building and sustaining diverse functioning networks using social media and digital platforms to improve diversity and inclusivity. Front Digit Humanit 5:1-11 (2018).

33 Montgomery BL, Dodson JE and Johnson SM, Guiding the way: mentoring graduate students and junior faculty for sustainable academic careers. SAGE Open 4 (2014).

34 Emery N, Hund A, Burks R, Duffy M, Scoffoni C and Swei A, Students as ecologists: strategies for successful mentorship of undergraduate researchers. Ecol Evol 9:4316-4326 (2019).

35 Friesner J, Colón-Carmona A, Schnoes AM, Stepanova A, Mason GA, Macintosh GC et al., Broadening the impact of plant science through innovative, integrative, and inclusive outreach. Plant Direct 5:1-28 (2021).

36 Henkhaus NA, Taylor CB, Greenlee VR, Sickler DB and Stern DB, Reinventing postgraduate training in the plant sciences: $\mathrm{T}$-training defined through modularity, customization, and distributed mentorship. Plant Direct 2:e00095 (2018).

37 Clair RS, Hutto T, MacBeth C, Newstetter W, McCarty NA and Melkers J, The new normal: adapting doctoral trainee career preparation for broad career paths in science. PLoS One 12:119 (2017).

38 Roberts AG, Industry and PhD engagement programs: inspiring collaboration and driving knowledge exchange. Perspect Policy Pract High Educ 22:115-123 (2018).
39 Rockinson-Szapkiw A, Wendt JL and Stephen JS, The efficacy of a blended peer mentoring experience for racial and ethnic minority women in STEM pilot study: academic, professional, and psychosocial outcomes for mentors and mentees. J STEM Educ Res (2021). https://doi.org/10.1007/s41979-020-00048-6.

40 Royal Society of Biology, Plant Health Undergraduate Studentships 2021. Available: https://www.rsb.org.uk/get-involved/grants/plant-healthug-studentships [25 May 2021].

41 John Innes Centre, International Undergraduate School. Available: https://www.jic.ac.uk/training-careers/summer-schools/internationalundergraduate/ [25 May 2021].

42 University of Helsinki, Master's Programme in Agricultural Sciences. Available: https://www2.helsinki.fi/en/admissions/degree-program mes/agricultural-sciences-masters-programme [28 May 2021].

43 Newcastle University, Agricultural and Environmental Science MSc. Available: https://www.ncl.ac.uk/postgraduate/courses/degrees/ag ricultural-environmental-science-msc [28 May 2021].

44 Montacute R, Holt-White E and Gent A, The University of Life: Employability and Essential Life Skills at University, The Sutton Trust, United Kingdom (2021). Available: https://www.suttontrust.com/wp-cont ent/uploads/2021/02/The-University-of-Life-Final.pdf

45 Picton J, The Turing scheme may not be as beneficial as the Erasmus+ scheme was. Epigram (2021). Available: https://epigram.org.uk/ 2021/04/30/untitled-157/

46 UKRI, Inspiring Images Throw Light on Agri-Food Research (2021). Available: https://www.ukri.org/news/inspiring-images-throw-light-onagri-food-research/ [22 April 2021]. 